\title{
The Conservation of Proboscis Monkey in Suwi River, East Kalimantan, Indonesia
}

\author{
Atmoko $\operatorname{Tr}^{1^{*}}{ }^{*}$ and Mukhlisi ${ }^{1}$ \\ ${ }^{1}$ Research and Development Institute of Natural Resources Conservation Technology, Jl. Soekarno \\ Hatta Km 38, PO BOX 578, Balikpapan 76112, Indonesia
}

\begin{abstract}
Suwi River, which is a part of Kenohan-Suwi Wetland in East Kutai District, East Kalimantan is a habitat of endangered animals such as proboscis monkey (Nasalis larvatus). Therefore, this study aims to determine the habitat, distribution, threats, and conservation efforts of proboscis monkeys in the Suwi River. To achieve this, the boat survey method was adopted, while plot line samples were used for vegetation analysis. The results showed that the habitat is composed of riverine plant species, such as prupuk (Mallotus sumatranus; IV=121.84\%), bungur (Lagerstroemia speciosa; IV=37.10\%), and rengas (Gluta renghas; $\mathrm{IV}=34.76 \%$ ). Furthermore, a minimum of 12 monkey groups was distributed in this area, however, their population is unknown. Illegal hunting by local people has caused population decline, this is in addition to other threats, such as habitat conversion, forest fire, and invasive plant species. The effort to protect the habitat of proboscis monkeys was made by developing Essential Ecosystem Areas Suwi-Mesangat. Other institutions that committed to protecting this area include Federal and local government, NGO, local community, and palm oil company
\end{abstract}

\section{Introduction}

Proboscis monkey (Nasalis larvatus) is one Borneo protected primates endemic. Their distribution is limited to the Borneo island, which includes three countries, namely Indonesia, Malaysia, and Brunei Darussalam. The Indonesian government protects proboscis monkeys based on Regulation number 7 of 1999. These monkeys are prohibited from being traded internationally and are included in Appendix I of CITES (Convention on International Trade in Endangered Species of Wild Fauna and Flora). It was also included in the category of endangered species based on the Red List IUCN (International Union for Conservation of Nature and Natural Resources) [1].

Their habitat on river banks and mangrove areas is converting more rapidly into residential/agricultural areas and while aquaculture, respectively. Approximately, forty percent has changed, and only $4.1 \%$ is in conservation areas [2], which has led to a decline in their population. In 1987, their population was estimated at 260,950, and about 25,625 were in conservation areas [3]. In less than 10 years, their population decreased to around

*Corresponding author: three.atmoko@gmail.com 
114,000 individuals, and only about 7,500 were in the conservation area [4]. Furthermore, their habitat, which is mostly outside the conservation area, is very vulnerable to damage.

One of the priority areas for the conservation of proboscis monkeys is the Mahakam River [5], with Kedang Kepala River as one of its tributaries, and Kenohan-Suwi Wetland is upstream. The Suwi River and its surrounding wetlands play an essential role in regulating the hydrological balance and habitat of the endangered species. As a basis for formulating a conservation strategy, initial information about the distribution, habitat, and potential threats of proboscis monkeys in the Suwi River needs to be known.

\section{Methods}

This study was carried out in July 2017 in the Suwi River, Muara Ancalong District, East Kutai Regency, East Kalimantan. It aims to determine the distribution and population of proboscis monkeys. To achieve this, the boat survey method was adopted by sailing the river using an engine boat in the morning and evening. The data recorded were coordinates, the number of monkeys, time of encounter, and activities undertaken. Furthermore, population and previous disturbances were obtained from interviews with local fishermen and those that owned floating huts in the Suwi River.

The habit of the proboscis monkey is divided into upstream and downstream riparian as well as middle areas (wet swamp). The structure and composition of plant species were determined by analyzing the vegetation using line plots sampling. There are six lines $(10 \mathrm{~m}$ wide) with a total length of observation paths of $1200 \mathrm{~m}(1.2 \mathrm{ha})$. The transect was divided into $20 \mathrm{~m} \times 20 \mathrm{~m}$ plots to record the vegetation at the tree and pole stage ( $>10 \mathrm{~cm}$ diameter). Also, a nested $5 \mathrm{~m} \times 5 \mathrm{~m}$ plots were made to record the vegetation of sapling level $(<10 \mathrm{~cm}$ diameter). The collected data include plant species, diameter at breast height (dbh), and tree height. Furthermore, data analysis was carried out to calculate the Importance Value Index (IV) of each plant species by adding their relative frequency (RF), relative density (RD), and relative dominance (RDo) [6]. Data on plant species were collected outside the observation plot along the Suwi river banks by boat. The species of food plants were determined through direct observation using binoculars. Also, food plant preference is based on the frequency with which individual monkeys eat certain plants. Further identification was carried out at the Herbarium Wanariset (WAN).

\section{Results}

\subsection{The Distribution of Proboscis Monkey}

Proboscis monkeys are found along the Suwi River and its wetland surroundings. Observation results estimated 12 groups of this species, however, their population was not estimated (Fig. 1). The obstacle encountered is the difficulty in identifying the presence of proboscis monkeys during a short survey. This is because they do not return to the river's sleeping tree in the afternoon, and sleep elsewhere which is not detected during the river tracing. 


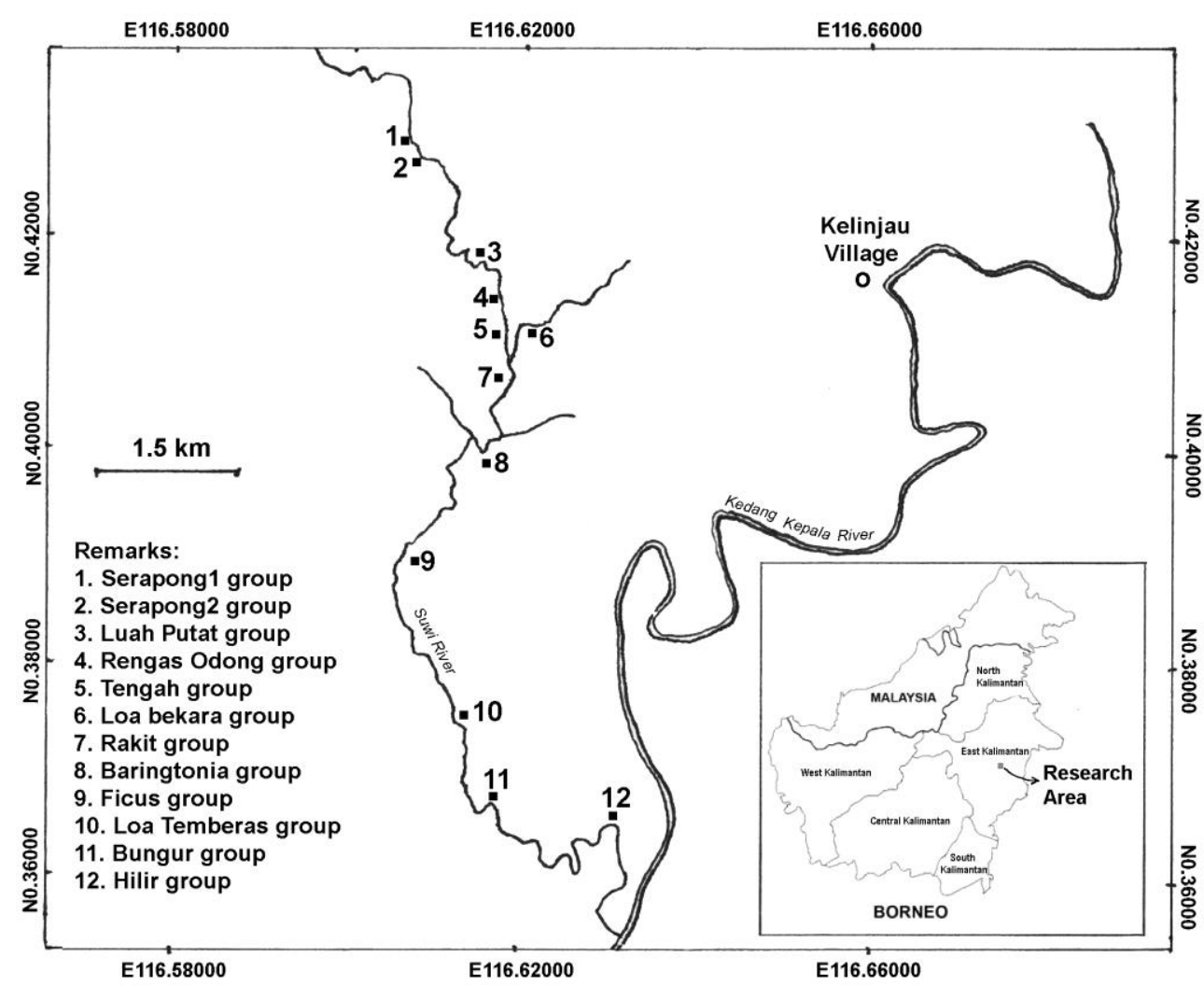

Fig. 1. The distribution of proboscis monkey groups in Suwi River

\subsection{Habitat and food plant}

At least 60 plant species were recorded in the Kenohan-Suwi Wetland, 32 were in the vegetation analysis plot. Furthermore, the upstream proboscis monkeys, adjacent to the planting area of oil palm companies have the highest damage level than the middle and downstream.

The analysis showed that the vegetation of the dominant tree-level was Mallotus sumatranus $(\mathrm{IV}=121.84 \%)$, Lagerstroemia speciosa $(\mathrm{IV}=37.10 \%)$, and Gluta renghas (IV $=34.76 \%$ ). The pole level (small trees) was dominated by Mallotus sumatranus (IV = $108.08 \%)$, Barringtonia acutangula $(\mathrm{IV}=36.36 \%)$, and Dillenia excelsa $(\mathrm{IV}=29.24 \%)$. Meanwhile, the sapling level was dominated by Mallotus sumatranus (IV $=117.00 \%$ ), Barringtonia acutangula (IV $=36.36 \%)$, and Lepisanthes alata $(\mathrm{IV}=28.30 \%)$. In addition, Mimosa pigra has spread and dominates the burnt area, while the Salvinia molesta covers part of the water's surface.

A total of 12 plant species of feed sources were identified as shown in Table 1). However, analyzing the temporary data for food preference was impossible because it has limited. Therefore, further observation of the behaviors of proboscis monkeys is needed to utilize plants in their habitat as food.

During the field survey, most of the plants were flowering and fruiting, however, there was a relatively short time. Furthermore, several plants species that are considered important in the Suwi Wetland are collected for the Wanariset herbarium. In addition, fairly complete photo documentation is obtained for most of the existing plants' fruit and/or flowers. This information has been published in a book [7]. 
Table 1. The Species of proboscis monkeys food plant in the Suwi River

\begin{tabular}{llll}
\hline Habitat & \multicolumn{1}{c}{ Familly } & \multicolumn{1}{c}{ Species } & \multicolumn{1}{c}{ Eaten parts } \\
\hline Upper & Lauraceae & Litsea oppositifolia & Flower \\
Upper & Phyllanthaceae & Glochidion littorale & Leaf \\
Upper & Vitaceae & Cayratia trifolia & Leaf, flower \\
Middle & Anacardiaceae & Mangifera gedebe & Leaf, flower \\
Middle & Rubiaceae & Gardenia tubifera & Leaf \\
Middle & Leguminosae & Crudia beccarii & Fruit \\
Middle & Dilleniaceae & Dillenia excelsa & Leaf \\
Middle & Clusiaceae & Garcinia parvifolia & Leaf, flower \\
Lower & Moraceae & Ficus benjamina & Leaf \\
Lower & Moraceae & Ficus sp. & Leaf \\
Lower & Lecythidaceae & Barringtonia acutangula & Leaf \\
Lower & Euphorbiaceae & Mallotus sumatranus & Leaf \\
\hline
\end{tabular}

\subsection{The threats}

\subsubsection{Illegal Hunting}

Based on the information from the local community, in 2013, there was a massive hunt for proboscis monkeys in the Suwi River by the Dayak tribe (Mekar Village and Long Lees Village). They hunt for meat using poisonous chopsticks to be mixed with pork for sale. This activity is carried out at night when the proboscis monkeys are in their sleeping trees by the river. Hunting takes place quietly to prevent panic in the group of proboscis monkeys, this allows the hunters to target and drop them one after the other from their sleeping tree.

Regarding the number of proboscis monkeys been hunted at that time, a local fisherman (Mr. Amat) of the Suwi river that is resident for a long time in Kelinjau gave testimony. According to Mr. Amat, the hunters capture 10 to 15 proboscis monkeys that fill their 10meter longboat for each hunt. It is estimated that they hunt not less than 10 times. Furthermore, the hunted proboscis monkeys in the Suwi wetlands at that time ranged from 100 to 150 individuals. This information shows that the Suwi wetland was an essential habitat for proboscis monkeys with a reasonably high population and easy to find.

The hunt ended after Yasiwa (Yayasan Khatulistiwa Indonesia) raised public awareness regarding the importance of biodiversity in the Suwi Wetland ecosystem. Yasiwa is a local NGO that cares about the sustainability of local communities' livelihoods on the Suwi River and the conservation of proboscis monkeys. However, this does not preclude the repetition of the hunting, therefore, public awareness needs to continue.

Currently, proboscis monkeys in the Suwi River are difficult to find, their natural behavior changes, their age structure is estimated to be unhealthy, and the population is recovering. Furthermore, there have been several changes in the behavior of the proboscis monkeys in the Suwi wetlands, these include:

- High sensitivity to the presence of humans. In general, proboscis monkeys will immediately evade if a boat approaches.

- They use sleeping trees that are on the second layer of the river bank. Meanwhile, in general, proboscis monkeys use sleeping trees on the riverbank.

- Field observations show that their group movement is fast, mostly when foraging. 


\subsubsection{Habitat Conversion}

Currently, the habitat of proboscis monkey only exists in the riparian area of the Suwi River, while the surrounding forest has become concession areas for oil palm companies. This condition restricts their movement in their activities and maintains a source of feed.

\subsubsection{Forest Fire}

The Suwi River and the surrounding wetlands are fishing areas for local people. Every dry season, the bushes are burnt to open access when they are fishing in the rainy season. Unfortunately, the fire is often out of control and burn most of the existing forest

\subsubsection{Invasive Plant Species}

There are invasive plant species in the Suwi wetland. These include Salvinia molesta, which has spread to cover the waters in the Suwi wetlands, and M. pigra in the open area where land fires have been burned.

\section{Discussions}

The reoccurring hunting activities in the Suwi River have made proboscis monkeys sensitive, they respond to human presence with alert and avoidant behaviour. Furthermore, proboscis monkeys generally use riverside trees as sleeping trees [8]; however, due to hunting activities, they now use trees in the second layer of the river banks for sleeping locations.

The type of habitat for the proboscis monkeys in the Suwi River is riparian forest and the number of plant species in this area is lower than in Sukau, Sabah, which consisted of 109 species from 37 families [9], and Menanggul River, Sabah consists of 180 from 46 families [10]. The high number of plant species increases the variety of food sources for proboscis monkeys.

Salvinia molesta and M. pigra are two species that are invasive at the study site $[11,12]$. Currently, their existence is not yet a cause for concern; however, they need to be watched out for because they are invasive species in the Suwi Wetland. Furthermore, the closure of Suwi waters by $S$. molesta will impact the closure of waters preventing the passage of sunlight. This condition inhibits the growth of phytoplankton and zooplankton, a source of food for fish in the Suwi Wetland. The existence of oil palm plantations in the upstream area will supply the remaining fertilizer to the waters, which fertilizes $S$. molesta. Meanwhile, $M$. pigra is thought to have spread widely after a fire, causing tree crowns to open up and potentially disrupting natural succession.

Burning the land in preparation for plantation is the biggest threat to the population of Indonesia's proboscis monkey [13]. Therefore, rehabilitation activities need to be carried out in the Suwi wetland to restore forest cover after burning or clearing areas. In line with this, Yasiwa and local communities have carried out rehabilitation activities, however, they failed because of the high level of water fluctuation. During the rainy season, the land is covered with water up to $2 \mathrm{~m}$, and the plants will be submerged and die. So far, efforts to carry out rehabilitation with cuttings of Dillenia excelsa approximately $2 \mathrm{~m}$ long have been the most successful. The formation of tree canopy through rehabilitation is expected to suppress and kill M. pigra.

The use of a single species, $D$. excelsa, for rehabilitation is not appropriate because it creates a monoculture of the ecosystem. Therefore it is necessary to use several other local species, such as Mallotus sumatranus, Barringtonia acutangula, and Syzygium lineatum. In addition, planting is carried out alternately, to produce heterogeneous stands. 
The Suwi River and the surrounding wetlands (Lake Mensangat) are essential ecosystems that can be managed. An essential ecosystem is ecologically, socially, economically, and culturally important for conserving and are located outside the conservation area. Furthermore, the Suwi-Mensangat wetland is an essential area for three reasons. First, it is the habitat of endangered and protected species, namely proboscis monkeys (Nasalis larvatus; endangered species) and siam crocodiles (Crocodylus siamensis; Critically endangered). Second, it is an area that is important in regulating the hydrological system. Third, it meets the vital need of the local communities and also the Suwi wetland is a habitat for various animals. There are at least 1263,9 , and 38 species of mammals, birds, reptiles, and fishes, respectively [14]. Furthermore, the KEE Mensangat-Suwi includes four concession areas for oil palm companies, therefore, its management needs to be done collaboratively. Federal and local government, NGOs, local communities, and palm oil companies have joined effort and are committed to protecting the Essential Ecosystem Areas (Kawasan Ekosistem Essential/KEE) Suwi Mesangat. Private oil palm plantation companies also need to be involved in preserving proboscis monkeys and their habitats in their concession areas in the form of CSR funding support for nature conservation [15].

\section{Conclusion}

The habitat of the proboscis monkey in the Suwi River with over 60 plant species still provides a potential source of food to support the lives of existing proboscis monkeys. Furthermore, the destruction of forests due to fire needs rehabilitation efforts through the use of dominant native species such as Dillenia excels, Mallotus sumatranus, Barringtonia acutangula, and Syzygium lineatum. However, it is necessary to be aware of the potentially invasive species such as Salvinia molesta and Mimosa pigra. The loss and destruction of habitat also need to be prevented by involving various companies holding concession areas to carry out conservation efforts in the concept of managing essential ecosystem areas.

\section{References}

1. R. Boonratana, S.M. Cheyne, C. Traeholt, V. Nijman, J. Supriatna. IUCN Red List Threat. Nasalis larvatus (2020)

2. J.A. McNeely, K.R. Miller, W.V. Reid, R.A. Mittermeier, T.B. Werner. Conserving The World's Biological Diversity. IUCN, Gland, Switzerland; WRI, CI, WWF-US, and the World Bank, Washington, D.C. (1990).

3. MacKinnon. Primate Conservation 8:175-183. (1987)

4. M. Bismark. Rimba Indonesia 30:3 (1995)

5. E. Meijaard, V. Nijman. Biol Conserv 92:15-24. (2000)

6. A. Susilowati, H.H. Rachmat, D. Elfiati, C.R. Kholibrina, Y.S. Kusuma, H. Siregar. Biodiversitas 20:1681-87 (2019)

7. Mukhlisi, T. Atmoko, Priyono. Flora di Habitat Bekantan Lahan Basah Suwi, Kalimantan Timur. Bogor: Forda Press. (2018)

8. H. Bernard, I. Matsuda, G. Hanya, A.H. Ahmad. Int J Primatol. 32(1):259-267. (2011)

9. R. Boonratana. Malayan Nat. J. 54(4):271-28. (2000)

10. I. Matsuda, A. Tuuga, S. Higashi. Am J Primatol. 71(6):478-492. (2009)

11. S. Li, P.Wang, Z. Su, E. Lozano, O. LaMaster, B. Jason. Grogan, Y. Weng, T. Decker, John F., M. McGarrity. Scientific Reports 8:8006. (2018)

12. I, Uko, A.C. Amadioha, H. Okolie, N.J. Int J Agri Biosci, 9(2): 95-102. (2020) 
13. D.J. Stark, V. Nijman, S. Lhota, J. Robins, B. Goossens. Endanger Species Res. 16(1):31-43. (2012)

14. D. Wahyudi, M. Kusneti, Suimah. 1813(1) p. 020013). AIP Publishing. (2017)

15. T. Atmoko, A. Mardiastuti, M. Bismark, L.B. Prasetyo, E. Iskandar. Biodiversitas 21: 5155-5163. (2020) 